\title{
数値重み関数法による構造解析手法の開発
}

\section{- 2 次元弾性および平板構造解析の定式化一}

\author{
正員 角 洋一 ${ }^{*}$ 学生員 A.T.M.M. Anowarul Bashar ${ }^{* *}$ \\ 正員 川村 恭已*
}

Numerical Weight Function Method for Structural Analysis

- Formulation for two-dimensional elasticity and plate structuresby Yoichi Sumi, Member A.T.M.M. Anowarul Bashar, Student Member
Yasumi Kawamura, Member

\begin{abstract}
Summary
The weight function method was originally derived for two- and three-dimensional crack problems to calculate stress intensity factors for arbitrary loading conditions. In the present paper the weight function method has been generalized to the response analysis of structures basing upon the Maxwell-Betti's reciprocal theorem, where the weight function method is formulated and applied to two-dimensional elasticity and plate bending problems with illustrative examples. The method is very useful for the analysis of structures subjected to a variety of loading conditions, because once the weight function is calculated the responses such as displacements and stresses may simply be calculated by the integration of the inner product of the universal weight function and a load vector.
\end{abstract}

\section{1. 緒 言}

重み関数法は1970 年代にき裂の応力拡大係数解 析への適用を目的として研究された手法であり、そこで は、物体形状と幾何学的境界条件に対応して固有に定ま るベクトル場（重み関数）を用いて任意の荷重条件に対 するき裂の応力拡大係数が、重み関数と荷重ベクトルの

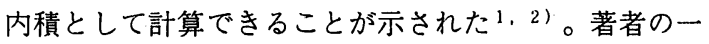

* 横浜国立大学大学院工学研究院

** 横浜国立大学大学院工学研究科博士後期課 程

原稿受理 平成 15 年 1 月 10 日
人は最近、この重み関数法を任意の 3 次元き裂の応力拡 大係数算定に適用する手法を開発したが3)、本研究では、 この考え方が、さらに一般の構造応答、即ち注目点の変 位や応力の計算にも適用可能なことを示す。一度、構造 形状と幾何学的境界条件のみに依存する固有のベクト ル場としての重み関数が決定されると、それと荷重べク トルの内積の積分が、注目点における応答（変位あるい は応力）を与えることになるので、多数の荷重系を扱う 必要のある場合、本手法の有効性が高い。船舶海洋構造 の疲労強度の直接計算では、 1,000 以上の極めて多数の 荷重ケースを扱わなければならない場合があるが、構造 危険部位が明確で限定的な場合には本手法は有効な解 析手段を提供すると考えられる。 
本論文では、2 次元弾性問題および板曲げ問題の重み 関数法の定式化を行うとともに、一般の 3 次元板骨構造 への拡張を論ずる。さらに本手法を沉用構造解析コード と組み合わせてシステム化し、数値計算による重み関数 算定精度の検証を行い、本手法の有効性を示す。

\section{2. 構造応答解析のための重み関数法の定式化}

\section{1 平板模造応答解析の亚み网数法の定式化}

平板の構造応答は、微小変位の場合面内応答と面外応 答を分離して議論できるので、以下では、2 次元弾性問 題と板曲げ問題に分けて重み関数法の定式化を行う。座 標系としてFig.1 あるいはFig. 2 に示すように、平板の 中央面内に $x_{1}, x_{2}$ 軸あるいは $x, y$ 軸をとりこれらと右手 系をなすように $x_{3}$ 軸あるいは $z$ 軸をとる。以下の議論で は、簡明性のため 2 次元弾性問題の記述には $O-x_{1} x_{2} x_{3}$ 座 標系と変位および応力のテンソル表示を、また板曲げ問 題には $\mathrm{O}-x y z$ 座標系と工学表示を併用するが、混乱は無 いと思う。

\subsubsection{2 次元弾性問題の定式化}

解析対象としてFig. 1 に示す 2 次元領域 $V$ を考えよう。 解くべき境界値問題は通常のテンソル記号と総和規約 を用いて

$$
\begin{array}{ll}
\sigma_{i j, j}+f_{i}=0 & \text { in } \mathrm{V} \\
\sigma_{i j j_{j}}=t_{i} & \text { on } \mathrm{S}_{\mathrm{t}} \\
u_{i}=v_{i} & \text { on } \mathrm{S}_{\mathrm{u}}
\end{array}
$$

と表せる。ここに、物体力を $f_{\mathrm{i}}$ 、応力境界 $\mathrm{S}_{\mathrm{t}}$ に作用する 表面力を $t_{\mathrm{i}}$ 、変位境界上の強制変位を $v_{\mathrm{i}}$ とし、得られる 変位および応力をそれぞれ、 $u_{\mathrm{i}} 、 \sigma_{\mathrm{ij}}$ とする。また、応力 および変位の評価点を P と表すことにする。

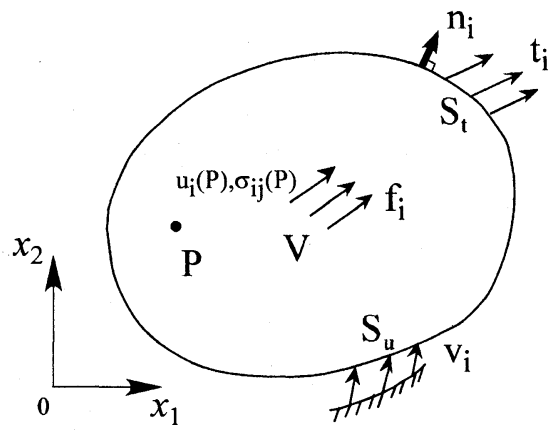

Fig.1 Original boundary value problem

次に、補助問題として、点 $\mathrm{P} に x_{\mathrm{k}}$ 方向の単位集中力が
作用する問題を定義しよう(Fig. 2)。

$$
\begin{array}{ll}
\sigma_{i j, j}+\delta_{i}^{(k)}(\mathrm{P})=0 & \text { in } \mathrm{V} \\
\sigma_{i j} n_{j}=0 & \text { on } \mathrm{S}_{\mathrm{t}} \\
u_{i}=v_{i} & \text { on } \mathrm{S}_{\mathrm{u}},
\end{array}
$$

ここに、 $\delta_{i}^{(\mathrm{k})}(\mathrm{P})$ は点 $\mathrm{P}$ に作用する $x_{\mathrm{k}}$ 軸方向の単位集中 力を表す。この問題の変位解を $u_{i}{ }^{(\mathrm{k})}(\mathrm{Q} ; \mathrm{P})$ と表す。

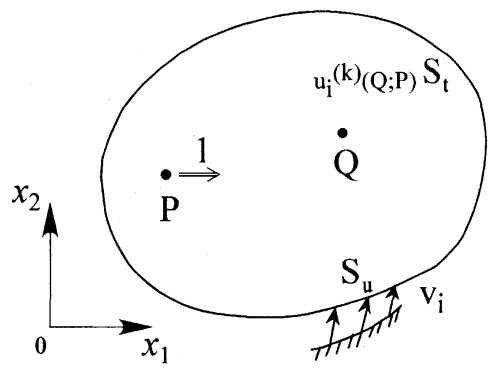

Fig. 2 Auxiliary boundary value problem for $\mathrm{k}=1$

このとき、問題(1) と（2)に Maxwell-Betti の相反定理 を適用すると、

$$
\begin{aligned}
u_{i}(\mathrm{P})= & \int_{V} u_{l}^{(i)}(\mathrm{Q} ; \mathrm{P}) f_{l}(\mathrm{Q}) d V(\mathrm{Q}) \\
& +\int_{S_{t}} u_{l}^{(i)}(\mathrm{Q} ; \mathrm{P}) t_{l}(\mathrm{Q}) d S(\mathrm{Q})
\end{aligned}
$$

を得る。明らかに、 $u_{1}^{(\mathrm{i})}(\mathrm{Q} ; \mathrm{P})$ は点 $\mathrm{P}$ の変位 $u_{i}(\mathrm{P})$ の重み関 数となることがわかる。

応力は、式(3)で与えられる変位に対して、変位-ひず み関係と応力ーひずみ関係を適用して

$$
\sigma_{i j}(P)=\frac{1}{2} E_{i j m n}\left(u_{m, n}+u_{n, m}\right)
$$

と定められる。ここに、 $E_{\mathrm{ijm} n}$ は弾性係数テンソルである。 式(4)右辺の変位の偏微分は

$$
\begin{aligned}
u_{m, n}(\mathrm{P})= & \int_{V} u_{l, n}^{(m)}(\mathrm{Q} ; \mathrm{P}) f_{l}(\mathrm{Q}) d V(\mathrm{Q}) \\
& +\int_{S_{t}} u_{l, n}^{(m)}(\mathrm{Q} ; \mathrm{P}) t_{l}(\mathrm{Q}) d S(\mathrm{Q})
\end{aligned}
$$

と表せるので、これを式(4)に代入すると

$$
\begin{aligned}
\sigma_{i j}(\mathrm{P})= & \int_{V} h_{i j l}(\mathrm{Q} ; \mathrm{P}) f_{l}(\mathrm{Q}) d V(\mathrm{Q}) \\
& +\int_{S_{t}} h_{i j l}(\mathrm{Q} ; \mathrm{P}) t_{l}(\mathrm{Q}) d S(\mathrm{Q})
\end{aligned}
$$


を得る。ここに、 $h_{\mathrm{ij} 1}$ は応力応答の重み関数であり、

$$
h_{i j l}(\mathrm{Q} ; \mathrm{P}) \equiv \frac{1}{2} \mathrm{E}_{i j m n}\left\{u_{l, n}^{(m)}(\mathrm{Q} ; \mathrm{P})+u_{l, m}^{(n)}(\mathrm{Q} ; \mathrm{P})\right\}
$$

と定義される。式(7)右辺の |\} 内に現れる変位の偏微分 は点 $\mathrm{P}$ に作用する $x_{\mathrm{m}}$ 座標軸方向の単位集中力による変 位の $x_{\mathrm{n}}$ 座標軸方向の偏微分であるから $\mathrm{m}=1$ の場合、物 理的には Fig.3に示す力対系の誘起する変位場を表す。 例えば、 $\mathrm{m}=\mathrm{n}=1$ のとき、

$$
\begin{aligned}
u_{l, 1}^{(1)}(\mathrm{Q} ; \mathrm{P}) & =\lim _{\Delta x_{1} \rightarrow 0}\left\{u_{l}^{(1)}\left(\mathrm{Q} ; \mathrm{P}\left(\mathrm{x}_{1}+\Delta \mathrm{x}_{1}, \mathrm{x}_{2}\right)\right)\right. \\
& -u_{l}^{(1)}\left(\mathrm{Q} ; \mathrm{P}\left(\mathrm{x}_{1}, \mathrm{x}_{2}\right)\right\} / \Delta \mathrm{x}_{1}
\end{aligned}
$$

であり、上式から式(8)の算定には力対による差分近似が 可能なことがわかる。
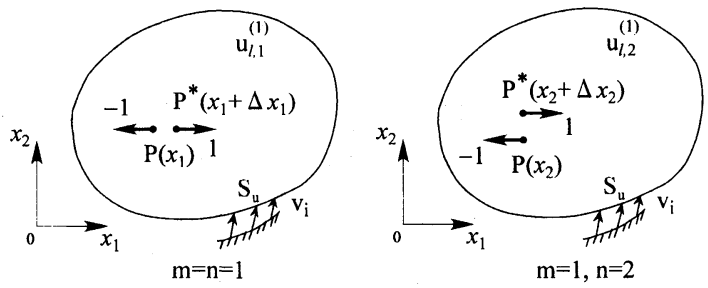

Fig.3 System of force couples for stress weight function

\subsection{2 板曲け問題の定式化}

次に、解析対象として、周辺を適宜支持あるいは固定 された弾性平板に対して前節と同様の考察を加える。こ の平板が、Fig.4に示されるように、任意の領域 $\mathrm{S}(\mathrm{Q})$ に 作用する分布荷重 $p(\mathrm{Q})$ を受ける場合、点 $\mathrm{P}$ の変位 $w(\mathrm{P})$ を求める問題が与えられたとしよう。一方、補助問題と して点 $\mathrm{P} に$ 単位集中力をかけた時の領域 $\mathrm{S}(\mathrm{Q})$ における変 位を $w(\mathrm{Q} ; \mathrm{P})$ と表し、これらの問題にMaxwell-Betti の相 反定理を適用すると、

$$
\mathrm{w}(\mathrm{P})=\int_{S_{(\mathrm{Q})}} p(\mathrm{Q}) \mathrm{W}(\mathrm{Q} ; \mathrm{P}) d S(\mathrm{Q})
$$

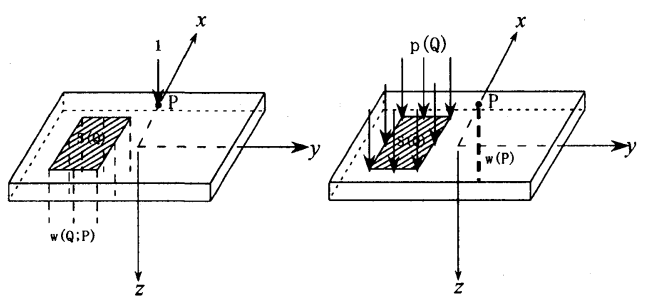

Fig.4 Original problem and auxiliary problem
$w(\mathrm{Q} ; \mathrm{P})$ が点 $\mathrm{P}$ の変位応答の重み関数となることを意味し ている。

次に、曲げモーメント、据りモーメント、せん断力な どの内力の重み関数について考察する。領域 $\mathrm{S}(\mathrm{Q})$ に作用 する分布荷重 $p(\mathrm{Q})$ による点 $\mathrm{P}$ の曲げモーメント $M_{\mathrm{x}}$ は式 (9)の関係を用いて

$$
\begin{aligned}
M_{x}(P) & =-D\left(\frac{\partial^{2} \mathrm{w}(\mathrm{P})}{\partial x^{2}}+v \frac{\partial^{2} \mathrm{w}(\mathrm{P})}{\partial y^{2}}\right) \\
& =\int_{S_{\mathrm{Q}}} p(\mathrm{Q})\left[-D\left(\frac{\partial^{2} \mathrm{w}(\mathrm{Q}: \mathrm{P})}{\partial x^{2}}+v \frac{\partial^{2} \mathrm{w}(\mathrm{Q}: \mathrm{P})}{\partial y^{2}}\right)\right] d S(\mathrm{Q})
\end{aligned}
$$

と表すことができる。この時、右辺[]内を、点Pにおけ る曲げモーメント $M_{\mathrm{x}}$ の重み関数と考えることができる ので、これを $W_{\mathrm{Mx}}$ と表わすと、任意の荷重系 $p(\mathrm{Q})$ による 点 $\mathrm{P}$ の曲げモーメント $M_{\mathrm{x}}(\mathrm{P})$ は、

$$
\begin{aligned}
& M_{x}(\mathrm{P})=\int_{S_{\mathrm{Q}}} p(\mathrm{Q}) \cdot W_{M x}(\mathrm{Q}: \mathrm{P}) d S(\mathrm{Q}) \\
& W_{M_{x}}=-D\left(\frac{\partial^{2} \mathrm{w}(\mathrm{Q} ; \mathrm{P})}{\partial x^{2}}+v \frac{\partial^{2} \mathrm{w}(\mathrm{Q} ; \mathrm{P})}{\partial y^{2}}\right)
\end{aligned}
$$

となる。重み関数を定義する変位 $w(\mathrm{Q} ; \mathrm{P})$ の偏微分は、点 $\mathrm{P}$ に作用する単位集中力の作用点位置が $x$ または $y$ 方向 へ変化する時の変位変化率であるから、

$$
\begin{aligned}
W_{M x}= & -D \lim _{\Delta x, y \rightarrow 0}\left\{\frac{\mathrm{w}(x+\Delta x, y)-2 \mathrm{w}(x, y)+\mathrm{w}(x-\Delta x, y)}{(\Delta x)^{2}}\right. \\
& \left.+v \frac{\mathrm{w}(x, y+\Delta y)-2 \mathrm{w}(x, y)+\mathrm{w}(x, y-\Delta y)}{(\Delta y)^{2}}\right\}
\end{aligned}
$$

と表すことができる。上記偏微分を数值計算上 2 階差分 で近似すると、右辺第 1 項は Fig. 5、第 2 項は Fig.6 に 示すような $\mathrm{P}$ 点近傍における単位力対系の負荷に対する 応答と等価である。

同様の定式化により、曲げモーメント $M_{\mathrm{y}}$ およびねじ りモーメント $M_{\mathrm{x} y}$ も容易に定めることができるので、そ の詳細の導出は省略する。

せん断力 $Q_{\mathrm{x}} 、 Q_{\mathrm{y}}$ については、3 階微分量となるので、 3 階差分に対応する類似の力対系を導くことができる。 せん断力 $Q_{\mathrm{x}}$ の重み関数による表現を導くと

$$
Q_{x}(\mathrm{P})=\int_{S_{\mathrm{Q}}} p(\mathrm{Q}) W_{\mathrm{Q} x}(\mathrm{Q} ; \mathrm{P}) d S(\mathrm{Q})
$$

を得る。(9)式は、分布荷重 $p(\mathrm{Q})$ を受ける平板において 


$$
W_{\mathrm{Q}_{x}}=-D \frac{\partial}{\partial x}\left\{\frac{\partial^{2} \mathrm{w}(\mathrm{Q} ; \mathrm{P})}{\partial x^{2}}+\frac{\partial^{2} \mathrm{w}(\mathrm{Q} ; \mathrm{P})}{\partial y^{2}}\right\}
$$

となる。ここに、 $W_{\mathrm{Qx}}$ はせん断力 $Q_{\mathrm{x}}$ の重み関数である。
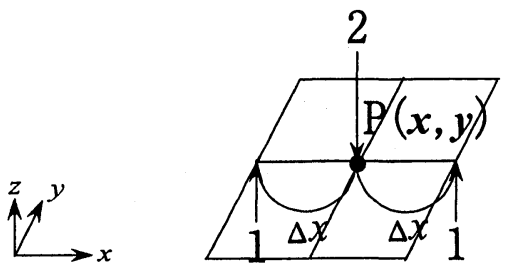

Fig.5. First force couple for $M_{\mathrm{x}}$

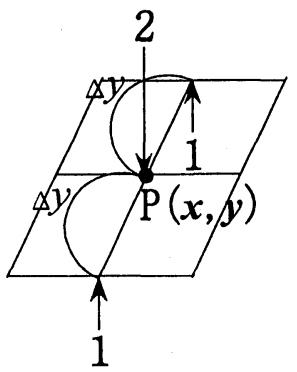

Fig.6. Second force couple for $M_{\mathrm{x}}$

\section{2 一般の 3 次元構造体への拡張}

重み関数による定式化を一般の 3 次元弾性体やシェ ルへ拡張可能なことは容易に推察されよう。ここでは、 一般の 3 次元空間内の弾性構造体において構造応答の 評価点近傍が、前述の面内および面外特性をもつ場合に 限定して議論を進める。このとき、この構造体に作用す る外力ベクトル $t_{\mathrm{i}}$ によって評価点 $\mathrm{P} に$ に生じる変位 $u_{\mathrm{i}}(\mathrm{P})$ と、 応答評価点に作用する前述の単位集中力による変位場 $u_{1}^{(\mathrm{i})}(\mathrm{Q} ; \mathrm{P}) に$ Maxwel l-Betti の相反定理を適用すると、

$$
\begin{aligned}
u_{i}(\mathrm{P})= & \int_{V} u_{l}^{(i)}(\mathrm{Q} ; \mathrm{P}) f_{l}(\mathrm{Q}) d V(\mathrm{Q}) \\
& +\int_{S_{\mathrm{t}}} u_{l}^{(i)}(\mathrm{Q} ; \mathrm{P}) t_{l}(\mathrm{Q}) d S(\mathrm{Q})
\end{aligned}
$$

を得る。したがって、注目点が一般の 3 次元構造体内に ある場合にも前節における変位や応力に対する重み関 数の定式化の議論がそのまま適用できることは明らか である。

\section{3. 数值計算と考察}

\section{1 重み関数の数值計算}

有限要素法による重み関数の算定と任意の荷重系に 対する評価点の変位および応力の計算手順は以下の通 りである。

（a）変位あるいは応力の応答評価点に、対応する前述の 単位集中力あるいは力対系を作用させ、汎用有限要 素解析プログラムなどで変位場を求める。これが、 対応する応答の重み関数べクトルとなる。このとき、 力対系を作用させる応答評価点近傍の節点配置を 座標軸方向に一致させるとともに要素寸法を適当 なものに選択する必要がある。

（b）構造体に作用する任意の荷重系に対する節点荷重 ベクトルを算出する。このとき、分布荷重に対する 節点荷重の積分にはガウス積分を用いる。

（c）上記 (a)、（b）で得られる重み関数ベクトルと荷重 ベクトルの内積をとると評価点における応答が直 ちに計算できる。

上記（a）は沉用構造解析プログラムで実行可能であ り、本研究では ANSYSを利用した。（b）は複雑な外力系 の場合計算が面倒ではあるが、何れにしても避けて通る ことのできないプロセスである。（c）は単純な内積計算 である。したがって、本計算法が有効なのは、応答評価 点が限定される一方、解くべき荷重系の数が極めて大き い場合となることが理解されよう。

\section{2 解析粠度の検証}

\section{2.12 次元弾性問題}

本手法の解析精度を検証するため、Fig.7 に示す円孔 を有する平板の一様引張りの問題を扱う。ここで、変位 および応力応答の注目点は図中の点 $\mathrm{P}_{\mathrm{i}}(\mathrm{i}=1,2,3)$ である。 計算に用いた要素分割を Fig.8 に示す。2.1.1 節で述べた ように単位集中力を節点力として点 $\mathrm{P}_{\mathrm{i}}$ に作用させるこ とによって、変位の重み関数が得られる。また、点 $\mathrm{P}_{\mathrm{i}}$ とこれに隣接する節点に作用する力対系による変位場 を重ね合わせることによって応力成分の重み関数が得 られる。

有限要素法により直接計算した変位および応力と重 み関数法により得られた結果の比較を Table1 に示す。 両者の差は極めて小さく計算精度は十分である。ひとつ 注意すべき点は、応力の重み関数を計算するに際して用 いる力対系を作用させる一対の節点の座標は、高精度で 座標軸方向に一致している必要があることである。本計 算では、倍精度レベルで座標値を一致させるようにした。 これによって、重み関数への誤差の混入を避けることが できた。 


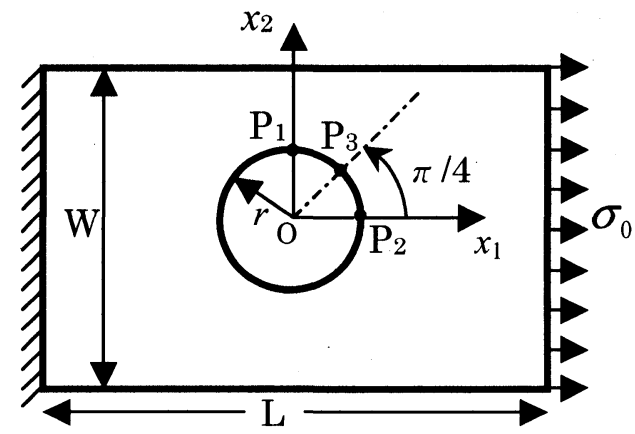

Fig.7 Rectangular plate with a circular hole subjected to uniform tension where points $\mathrm{P}_{1}, \mathrm{P}_{2}$ and $\mathrm{P}_{3}$ are the points of evaluation. $(\mathrm{L} / \mathrm{W}=2 ; \mathrm{r} / \mathrm{W}=0.25)$

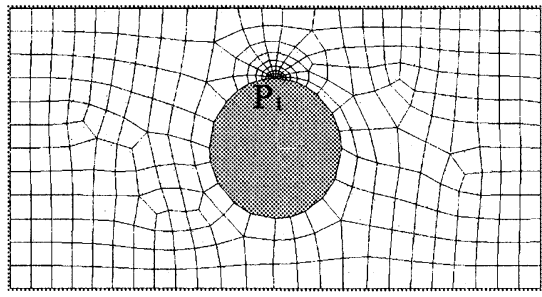

(a)

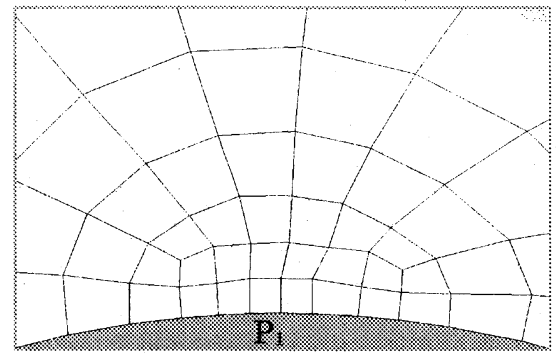

(b)

Fig.8 Mesh subdivision; (a) global mesh, (b) local mesh near the point $P_{1}$

Table 1 Comparison of response at the evaluation point

\begin{tabular}{|c|c|c|c|}
\hline Stress & Weight & Direct & Error \\
& function & FEM & $(\%)$ \\
\hline Point $\mathrm{P}_{1}\left(\sigma_{11} / \sigma_{0}\right)$ & 4.4510 & 4.4510 & $2.5576 \mathrm{E}-04$ \\
\hline Point $\mathrm{P}_{2}\left(\sigma_{22} / \sigma_{0}\right)$ & -1.7137 & -1.7137 & $-2.0881 \mathrm{E}-03$ \\
\hline Point $\mathrm{P}_{3}\left(\sigma_{12} / \sigma_{0}\right)$ & -0.9017 & -0.8982 & 0.3918 \\
\hline
\end{tabular}

\subsection{2 板曲げ問題}

Fig.9 に示す板厚 $\mathrm{t}$ の長方形板 $(a / b=2, t / b=0.01)$ の 4 辺を完全固定とし、中央集中荷重および一様分布荷重 に対する応答について、重み関数法と通常の有限要素解 析の結果との比較を行った。なお、ポアソン比 $\nu=0.3$ とした。図中点 $\mathrm{B}$ 、点 $\mathrm{C} 、$ 点 $\mathrm{D}$ においてそれぞれ曲げモ ーメント $M_{\mathrm{x}}\left(\mathrm{B}\right.$ 点)、 $M_{\mathrm{y}}\left(\mathrm{C}\right.$ 点)、ねじりモーメント $M_{\mathrm{xy}}(\mathrm{D}$ 点)を比較する。

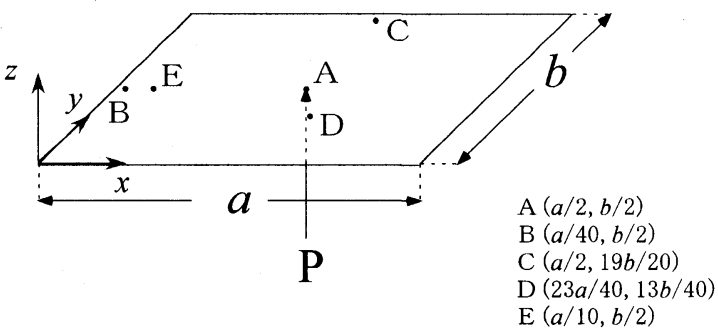

Fig.9 Rectangular plate subjected to lateral loading

Fig.9 に示すように荷重条件として、平板中央のA点 に大きさPの集中荷重を負荷した場合の重み関数法お よび有限要素法による直接算定の結果を比較し Table 2 に示す。わずかな誤差はあるものの、十分な精度がある ことが確認できる。

Table 2 Comparisons of weight function method and direct FEM for a concentrated force

\begin{tabular}{|c|c|c|c|}
\hline Moment & $\begin{array}{c}\text { Weight } \\
\text { function }\end{array}$ & $\begin{array}{l}\text { Direct } \\
\text { FEM }\end{array}$ & $\begin{array}{l}\text { Error } \\
(\%)\end{array}$ \\
\hline$M_{\mathrm{x}} / P$ at B & $-\mathbf{0 . 0 1 2 9 8}$ & -0.01295 & 0.234 \\
\hline$M_{\mathrm{y}} / P$ at $\mathrm{C}$ & -0.1258 & -0.1256 & 0.136 \\
\hline$M_{\mathrm{xy}} / P$ at D & 0.02846 & 0.02795 & 1.85 \\
\hline
\end{tabular}

重み関数法と直接有限要素計算の差の要因としては、 (a ) 有限要素法によって力対による応答変位を計算し 数值的に重み関数を求める際のメッシュサイズの影響、 (b)力対を構成する単位力の作用点間距離の影響、 が考えられる。先ず、要因 ( a ) について検討するため, 力対を構成する単位力間の距離 $\Delta x, \Delta y$ を一定 $(\Delta x / a=$ $\Delta y / a=1 / 20)$ とし、メッシュサイズを変化させて図中 E 点の曲げモーメント $\mathrm{M}_{\mathrm{x}}$ を重み関数法により計算した。な お、本計算ではすべての要素は正方形である。メッシュ サイズに対する有限要素法による直接計算結果との差 を Table 3 に示す。 $h / a=1 / 20$ ( $h$ : 要素サイズ)まで要 素を大きくすると誤差は $5 \%$ 程度まで拡大する。一方、 
メッシュを細かくするにつれて差は小さくなるものの、 $h / a=1 / 60$ 以下では $2 \%$ 程度の差で一定となる。

Table 3 Comparisons of $M x / P$ at point $E$ with $h / a$ by the weight function method and direct FEM

\begin{tabular}{|c|c|c|r|}
\hline$h / a$ & $\begin{array}{c}\text { Weight } \\
\text { function }\end{array}$ & $\begin{array}{c}\text { Direct } \\
\text { FEM }\end{array}$ & $\begin{array}{r}\text { Difference } \\
(\%)\end{array}$ \\
\hline $1 / 20$ & -0.01149 & -0.01099 & 4.53 \\
\hline $1 / 40$ & -0.01146 & -0.01116 & 2.65 \\
\hline $1 / 60$ & -0.01145 & -0.01119 & 2.30 \\
\hline $1 / 80$ & -0.01145 & -0.01121 & 2.18 \\
\hline $1 / 100$ & -0.01145 & -0.01121 & 2.13 \\
\hline $1 / 120$ & -0.01145 & -0.01121 & 2.10 \\
\hline
\end{tabular}

誤差要因 (b ) については、要素サイズを $h / a=1 / 80$ と 一定にして力対を構成する 2 節点間の距離 $\Delta x 、 \Delta y$ を変 化させ、その比較結果を Table 4 に示した。 $\Delta x / a, \Delta y / a$ を小さくすれば誤差も小さくなり、 $\Delta x / a=\Delta y / a=1 / 80$ では、誤差が約 $0.3 \%$ に減少し数值的重み関数が工学的 に十分な精度を有することが確認できた。

Table 4 Comparisons of $M x / P$ at point $\mathrm{E}$ with $\Delta x / a$ $(=\Delta y / a)$ by the weight function method and direct FEM

\begin{tabular}{|c|c|c|c|}
\hline $\begin{array}{c}\Delta x / a \\
=\Delta y / a\end{array}$ & $\begin{array}{c}\text { Weight } \\
\text { function }\end{array}$ & $\begin{array}{c}\text { Direct } \\
\text { FEM }\end{array}$ & $\begin{array}{c}\text { Error } \\
(\%)\end{array}$ \\
\hline $4 / 80$ & -0.01145 & -0.01121 & 2.18 \\
\hline $3 / 80$ & -0.01135 & -0.01121 & 1.29 \\
\hline $2 / 80$ & -0.01128 & -0.01121 & 0.65 \\
\hline $1 / 80$ & -0.01124 & -0.01121 & 0.28 \\
\hline
\end{tabular}

荷重条件が分布荷重の場合には式(11)，(14)のような 面積分が必要である。本計算では、要素毎に荷重と重み 関数の積をガウス積分して評価点の応答を求めた。数値 結果の一例として面上に $z$ 軸方向に $q$ なる一様分布荷重 が作用する場合の点 $\mathrm{B}$ 、点 $\mathrm{C}$ 、点 Dにおける曲げモーメ ント $M_{\mathrm{x}}\left(\mathrm{B}\right.$ 点)、 $M_{\mathrm{y}}\left(\mathrm{C}\right.$ 点)、ねじりモーメント $M_{\mathrm{xy}}(\mathrm{D}$ 点 $)$ の重み関数法と有限要素直接計算による結果の比較を Table 5 に示す。ねじりモーメントの誤差が一見大きく 見えるが、これは絶対值そのものが極めて小さいためで あり、実用上問題が無いことが確認できる。
Table 5 Comparisons of weight function method and direct FEM for a uniform pressure

\begin{tabular}{|l|c|c|c|}
\hline Moment & $\begin{array}{c}\text { Weight } \\
\text { function }\end{array}$ & $\begin{array}{c}\text { Direct } \\
\text { FEM }\end{array}$ & $\begin{array}{c}\text { Error } \\
(\%)\end{array}$ \\
\hline$M_{\mathrm{x}} / q b^{2}$ at B & -0.03660 & -0.03660 & 0.003 \\
\hline$M_{\mathrm{y}} / q b^{2}$ at C & -0.05856 & -0.05861 & 0.086 \\
\hline$M_{\mathrm{xy}} / q b^{2}$ at D & 0.00117 & 0.00112 & 4.016 \\
\hline
\end{tabular}

\section{4. 結論}

本研究では、数值重み関数法による構造解析手法の定 式化を 2 次元弾性問題および平板構造解析に対して行 い、汎用有限要素解析プログラムを用いた数值重み関数 算定システムを開発した。本手法を 2 次元弾性応力集中 問題、板曲げ問題に適用し、重み関数算定のための力対 の作用点位置と間隔、要素分割の解析精度に及ぼす影響 を検討した。これらの検討結果から、通常の有限要素解 析プログラムによって得られる数值重み関数を用いる ことにより、任意の荷重系に対して工学的に十分な計算 精度で解が得られることを確認した。

船舶海洋構造物の疲労解析で問題となる極めて多数 の荷重系に対する効率的解法の開発と構造危険部位に 高応力を誘起する荷重系の抽出に役立つシステムの開 発が今後の課題である。

\section{謝辞}

本研究は、運輸施設整備事業団基礎的研究推進制度 「船舶の構造健全性向上のための設計・検査評価手法の 高度化に関する研究」（課題番号：2001-03、総括研究 代表者：角 洋一）によるものである。本研究の数值計 算の一部は矢口真理、有本武樹両君の助力によるもので あり、ここに謝意を表します。

\section{考文献}

1) Bueckner, H.F., A novel principle for the computation of stress intensity factors. ZAMM 50, (1970), pp.529-545.

2) Rice, J.R., Some remarks on elastic crack-tip stress fields. International Journal of Solids and Structures, 8, (1972), pp.751-758.

3）角、樫内、伊藤、大倉、数値重み関数による 3 次元き裂解析の定式化、日本造船学会論文集 188 , 2000 , pp. 655-660. 